\title{
Evaluation of mercury concentration in the lake biwa-yodo river basin by a one-box multimedia model and model sensitivity on the experimentally determined water-sediment partition coefficient
}

\author{
B.H.A.K.T. Ariyadasa*, Akira Kondo, Hikari Shimadera, Hideki Ochi and Yoshio Inoue
}

*Correspondence: tharaka@ea.see.eng.osaka-u.ac.jp

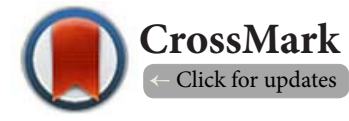

Graduate School of Engineering, Osaka University, Yamadaoka 2-1, Suita, Osaka, Japan.

\begin{abstract}
Considering the environmental damage caused by mercury, evaluating mercury concentrations in four environmental media, namely the atmosphere, water, soil, and sediment, is necessary. Available data on mercury emissions and computational modeling were used for this evaluation. Evaluating the sensitivity of the model for the water-sediment partition coefficient was another objective of this study. Recorded consumption and emission data of mercury were used to calculate the total annual emission amounts from 1959 to 2009 for the Lake Biwa-Yodo River basin of Japan, which was selected as the study site for this study. Laboratory-scale batch-shaking experiments were carried out to evaluate the partition coefficient of mercury between the aqueous and solid phase using soil, sediment, and sand samples. The experimentally determined partition coefficient was then incorporated into the one-box multimedia model. Mercury concentrations in this study site were calculated based on the calculated annual mercury emission data. The sensitivity of the model calculations on the partition coefficient was studied by comparing the calculated concentrations from different partition coefficient values with observed data. Calculated concentrations of mercury in all four environmental media were within the range of observed concentrations, and the performance of the model was validated. The results showed the accumulation of mercury in soil and sediment, and in the last 30 years, the mercury concentration has been constant, except in the atmosphere. Variations in atmospheric mercury concentrations were observed. Calculated concentrations for the representative partition coefficients for different soil types were compared with the environmental monitoring data. Improvements in the model performance due to the incorporation of an experimentally evaluated partition coefficient were confirmed. Thus, it was concluded that the one-box multimedia model could reliably calculate the environmental mercury concentrations based on the emission data. The sensitivity of the model was improved by using the experimentally evaluated partition coefficient value of mercury. Experimental evaluation of the other parameters used in the model calculations would further improve the model.
\end{abstract}

Keywords: Environmental modeling, lake biwa-yodo river basin, mercury, one-box multimedia model, partition coefficient

\section{Introduction}

Mathematical and computational modeling methods are used to evaluate the chemical pollution of our environment. Combined with improved management processes, we can now predict pollution conditions using environmental modeling. Various studies ranging from modeling macro-scale environmental issues such as global climate change to localized micro-scale environmental modeling assessments can be found in the scientific literature. In 1983, Hansen published a study on efficient three-dimensional global models for climate studies: Models I and II providethe proof of the geographical macro-scale of these studies [1]. In his review on the community multiscale air quality (CMAQ) modeling system, Byun describes the different components of chemical behaviors considered in air quality models [2]. In another study, Kondo published the use of the one-Box multimedia model(OBMM) to evaluate the lead concentration of the Lake Biwa-Yodo River basin(LBYRB) in Japan [3].
Mercury $(\mathrm{Hg})$ has caused serious environmental and health damage in Japan in the past. In 1956, a disease caused by methylmercury poisoning was discovered in Minamata city, which is located in the southwest region of Japan's Kyushu Island; this disease was later named Minamata disease [4]. Consumption and release of $\mathrm{Hg}$ has been legally controlled in Japan since 1973 [5], but still, many industries consume $\mathrm{Hg}$ in their production processes; thus, $\mathrm{Hg}$ appearsin the environmental analysis data [6]. The Japanese Ministry of Environment has set the environmental standards for the $\mathrm{Hg}$ concentration in water and soil to be less than $0.5 \mu \mathrm{g} \mathrm{L}^{-1}$ and for the alkyl mercury limit to be less than the detection limits [7]. In June 2013, a global treaty of The Minamata Convention on mercury was established and acknowledged by 96 countries (by February 2014) to protect human health and the environment from the adverse effects of $\mathrm{Hg}$ [8].

Monitoring environmental $\mathrm{Hg}$ in a large geographical region is not a very practical. The dispersion of $\mathrm{Hg}$ through environmental

(c) 2014 Ariyadasa et al; licensee Herbert Publications Ltd. This is an Open Access article distributed under the terms of Creative Commons Attribution License (http://creativecommons.org/licenses/by/3.0). This permits unrestricted use, distribution, and reproduction in any medium, provided the original work is properly cited. 
Ariyadasa et al. Journal of Environmental Engineering \& Ecological Science 2014,

transport mechanisms is one reason. An other reason is the impracticality of a government organization (i.e., the Ministry of Environment, Japan) to observe the occurrences of $\mathrm{Hg}$ all over the country through environmental monitoring. Considering the practical difficulty in monitoring the whole country for $\mathrm{Hg}$ occurrences and the adverse health effects of Hg such as carcinogenicity, child developmental defects, and toxic effects on nervous, digestive, and immune systems [9], it is importantto evaluate the concentration of Hg using environmental modeling. There are published model studies on the atmospheric transport and aquatic-soil systems of $\mathrm{Hg}[10,11]$, but a computational model that can combine all of the environmental media of the atmosphere, water, soil, and sediment was required. For this purpose, chemical behaviors and the transport mechanisms of $\mathrm{Hg}$ in all four environmental media were mathematically interpreted into an OBMM. The annual $\mathrm{Hg}$ emissions were estimated based on the available consumption and emission data from various data sources and used for the OBMM simulations to evaluate the concentration of $\mathrm{Hg}$.

Several chemical properties related to the metallic pollutants behavior, such as partition coefficient, dissolution coefficient, and diffusion coefficients, are required for these calculations $[\mathbf{3}, \mathbf{1 0}-\mathbf{1 3}]$. Because the water-sediment partition coefficient $\left(\mathbf{K}_{\mathbf{d}}\right)$ is important to interpret the chemical behavior of $\mathrm{Hg}[\mathbf{3}, \mathbf{1 0}-13]$, laboratory-scale batch-shaking experiments were carried out to determine the $\mathbf{K}_{\mathbf{d}}$ of $\mathrm{Hg}\left(\mathbf{K}_{\mathbf{d}(\mathbf{H g})}\right)$ using samples of soil. The experimentally determined $\mathbf{K}_{\mathbf{d}(\mathbf{H g})}$ value was incorporated into the OBMM calculations to improve the performance of the OBMM. The sensitivity of the OBMM to the $\mathbf{K}_{\mathbf{d}(\mathbf{H g})}$ value was evaluated by comparing the observed data for $\mathrm{Hg}$ concentrations in water and sediments with the calculated concentrations based on the experimental $\mathbf{K}_{\mathbf{d}(\mathbf{H g})}$ values obtained from other samples such as sediment and sand.

The Lake Biwa-Yodo River basin is an important geographic area with multiple land use patterns, including residential, agricultural, and industrial, on Japan's Main Island. It covers portions of six prefectures, namely Hyogo, Kyoto, Mie, Nara, Osaka, and Shiga, in the Kinki region. This study area lies between the latitudes 34.65 35.69 $\mathrm{N}$ and the longitudes $136.15 \sim 136.51^{\circ} \mathrm{E}$, while Lake Biwa, the largest natural water body in Japan, is located in the middle of this study area, covering $630.77 \mathrm{~km}^{2}$. The Seta River starts from the southern tip of Lake Biwa, turns into the Uji River, and then joins with the Kizu River and Katsura River to become the Yodo River, which flows to Osaka Bay [14]. This lake-river system also provides a natural drinking water source for a population of nearly 13 million in the Kinki region. Because of these important reasons, the LBYRB was selected as the study site. Figure 1 presents a diagram of the study area and the sampling points.

The main objectives of this study wereto evaluate the concentration of $\mathrm{Hg}$ in the LBYRB using an OBMM and to improve the OBMM calculation by incorporating the experimentally evaluated $\mathbf{K}_{\mathbf{d}(\mathbf{H g})}$ value.

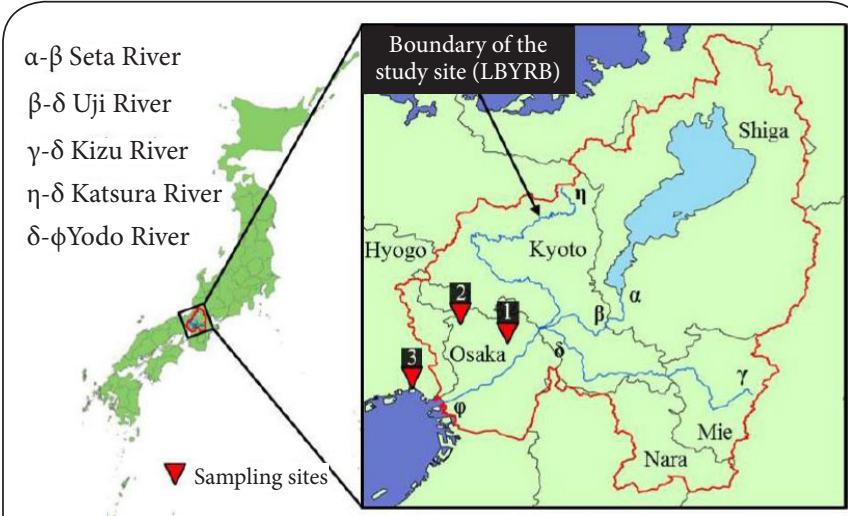

Figure 1. Diagram of the study site and the sampling points. $\alpha-\beta$ Seta River $\beta-\delta$ Uji River $\gamma-\delta$ Kizu River

$\eta-\delta$ Katsura River

$\delta-\varphi$ Yodo River

\section{Methodology}

Laboratory-scale batch experiments were carried out with soil to determine the water-sediment partition coefficient of $\mathrm{Hg}\left(\mathbf{K}_{\mathbf{d}(\mathbf{H g})}\right)$, and this value was incorporated into the OBMM calculations. Estimated annual emissions of $\mathrm{Hg}$ in the LBYRB were used as the input data and concentrations of $\mathrm{Hg}$ in the atmosphere, water, soil, and sediments in the LBYRB were calculated using a OBMM for a span of 50 years from 1959 to 2009. The accuracy of the OBMM calculations was evaluated by comparing the calculated $\mathrm{Hg}$ concentrations with the observed data for the year 2009. The model sensitivity to the $\mathbf{K}_{\mathbf{d}(\mathbf{H g})}$ was evaluated by comparing the calculated $\mathrm{Hg}$ concentrations with respective $\mathbf{K}_{\mathbf{d}(\mathbf{H g})}$ values, which were experimentally determined from sediments and sand samples collected from different locations in the study area. The study site is described in the introduction and the model is describedunder OBMM simulation section.

\section{Experimental evaluation of water-sediment partition coefficient \\ Materials and equipment}

A soil sample was collected from sampling points as shown in Figure 1 and cleaned Teflon containers were used to collect the samples. Temperature and $\mathrm{pH}$ of the collected sample were measured at the sampling points and a drying oven was used for drying the samples. Glass bottlesof $500 \mathrm{~mL}$ volumes were used for the shaking experiments which were performed with a thermostat shaker. Milli-Q water was used in the control experiments, and a standard mercury solution $\left(\mathrm{HgCl}_{2}\right.$ in $0.1 \mathrm{~mol} \mathrm{~L}^{-1}$. $\mathrm{HNO}_{3}\left(\mathrm{Hg}: 100 \mathrm{mg} \mathrm{L}^{-1}\right)$, purchased from Wako Pure Chemical Industries Ltd., Japan), was used for spiking of $\mathrm{Hg}$. Chemical analysis of the concentration of $\mathrm{Hg}$ was performed at a certified chemical analysis facility (Teijin Eco Science Ltd., Japan) using Atomic Absorption Spectroscopy (AAS) with a Mercury Analyzer following Japanese industrial standards $[15,16]$. 


\section{Experimental setup}

The experimental conditions and the experimental steps performed for the determination of the $\mathbf{K}_{\mathbf{d}(\mathbf{H g})}$ are shown in Figure 2. After the shaking experiments the samples were analyzed for the $\mathrm{Hg}$ concentrations in both aqueous and solid phases. Partition coefficients were calculated for each sub-sample, as shown in equation (1) by using the $\mathrm{Hg}$ concentrations in obtained from the chemical analysis $[17,18]$. After the preliminary evaluation, a secondary step was performed to confirm the results of the preliminary evaluation for longer shaking periods of 15,22 , and 30 days using similar experimental procedure for pretreating the four soil samples as referred to the secondary evaluation in the Figure 2.
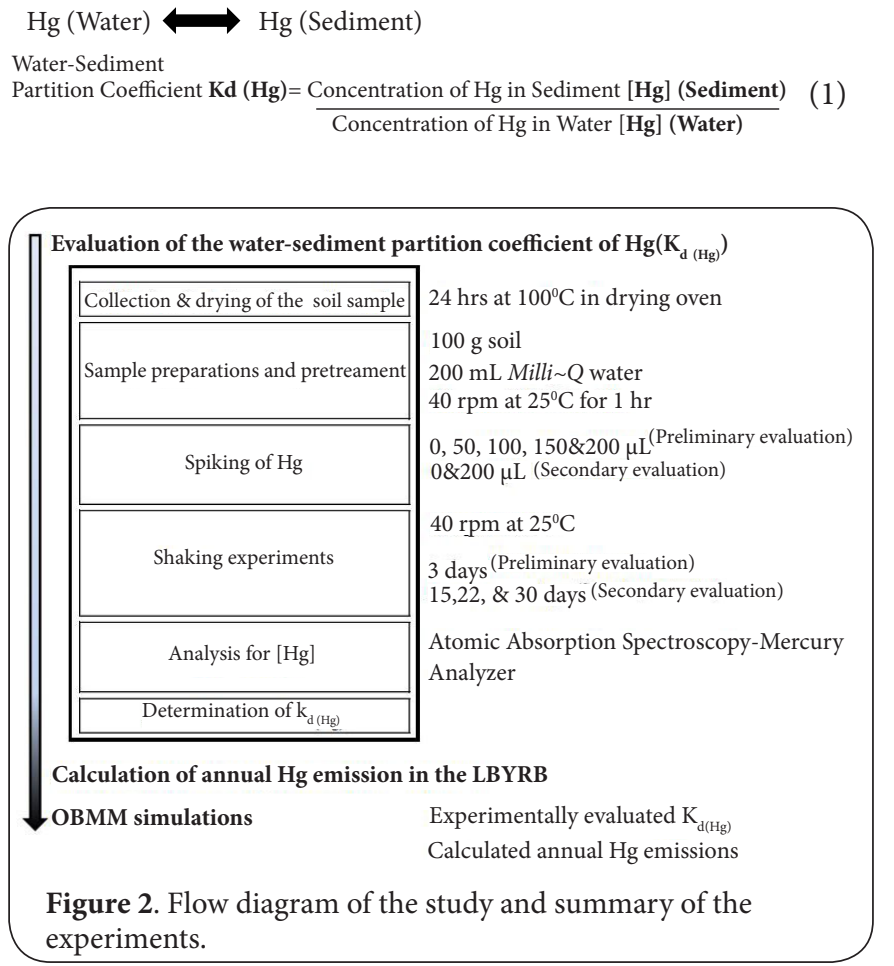

To observe the variations in the $\mathbf{K}_{\mathbf{d}(\mathbf{H g})}$ in other environments with different soil types, samples were collected from sampling points 2 and 3 , which represent sediment and sand. Experimental procedures similar to the preliminary evaluation were performed, and the representative $\mathbf{K}_{\mathbf{d}(\mathbf{H g})}$ values were calculated. These $\mathbf{K}_{\mathbf{d}(\mathbf{H g})}$ values were applied to the OBMM calculations at a later stage to evaluate the sensitivity of the OBMM to different $\mathbf{K}_{\mathbf{d}(\mathbf{H g})}$ values. Total organic carbon (TOC) was measured in all of the control samples according to the general rules for chemical analysis stated by the Japanese Industrial Standard Committee [15].

Hg emission amount calculation and OBMMsimulations Annual Hg emission amount calculations

Annual emissions of $\mathrm{Hg}$ from 1959 to 2009 were calculated for the LBYRB based on the records of $\mathrm{Hg}$ consumption and data from the Pollutant Release and Transfer Registry (PRTRwhich is maintained by the Japanese Ministry of Environment). From 1959 to 1990, the annual emissions of $\mathrm{Hg}$ were calculated based on the reported $\mathrm{Hg}$ consumptions for industries, catalysts, fertilizers, pharmaceuticals (inorganic chemicals), machinery, batteries, medical supplies (amalgam), explosives (gun powder), and paints $[19,20]$. The PRTR records the emissions under two categories: registered PRTR emissions and non-registered PRTR emissions [21].

\section{One-box multimedia model}

The study site is composed of four environmental media, which are the atmosphere, water, soil, and sediments, and is considered to be a three-dimensional, closed entity in this model. The nine chemical phenomena considered in the model calculations are emission, degradation, advection, sedimentation, re-suspension, dry/wet deposition, atmospheric mixing, and particle-ion exchange, which are diagramed in Figure 3. These calculations were performed based on the conditions that the $\mathrm{Hg}$ is in chemical equilibrium between the environmental media and observes the mass conservation law in the environmental systems. Time steps for these calculations were set to 6 minutes, and a series of differential equations was solved using the Runge-Kutta technique by a computer program coded in FORTRAN. The main equation of OBMM is given by the equation (2) and the main variables considered in these calculations are as follows:

(I) Emission of $\mathrm{Hg}$ into the atmosphere, soil, and water

(II) Degradation of $\mathrm{Hg}$ in all four environmental media

(III) Exchange of $\mathrm{Hg}^{+2}-\mathrm{H}_{\mathrm{g}(5)}$ within/between the environmental media

(IV) Transport of $\mathrm{Hg}$ by advection in the atmosphere

(V) Dry and wet deposition of $\mathrm{Hg}$ from the atmosphere

(VI) Sedimentation and re-suspension of $\mathrm{Hg}$ in water Utilization of an OBMM was previously published, and more details about the model can be found in Kondo et al., 2013 [3].

$$
d M_{i} / d t=\sum_{j=1}^{M N} f_{e q_{-} i, j}+f_{e m i_{-} i}+f_{a d_{-} i}+\sum_{j=1}^{M N} f_{d p s_{-} i, j}+\sum_{j=1}^{M N} f_{d e g_{-} i, j}
$$

Where $i, j$ is the environmental medium; $M N$ is the number of media; $M_{i}$ is the gross mass of $\mathrm{Hg}$ in medium $i(\mathrm{~mol}) ; f_{\text {eq } i, j}$ is the mass-transfer flux of $\mathrm{Hg}$ at equilibrium $\left(\mathrm{mol} \mathrm{s}^{-1}\right) ; f_{\text {emi }}^{\text {eq ilj }}$ the emission flux of $\mathrm{Hg}\left(\mathrm{mol} \mathrm{s}^{-1}\right) ; f_{a d}$ is the advection flux of $\mathrm{Hg}$ $\left(\mathrm{mol} \mathrm{s}^{-1}\right) ; f_{\text {dprs }}$ is the deposition flux of $\mathrm{Hg}\left(\mathrm{mol} \mathrm{s}^{-1}\right)$; and $f_{\text {deg }}$ is the degradation flux of $\mathrm{Hg}\left(\mathrm{mol} \mathrm{s}^{-1}\right)$. Detailed equations and the parameters are provided in Appendix 1 in the Supplementary Data.

The calculated annual emissions of $\mathrm{Hg}$ were entered into the OBMM, and the calculations were performed to evaluate the concentration of $\mathrm{Hg}$ in all four environmental media. Calculations were carried out with the experimentally determined $\mathbf{K}_{\mathrm{d}(\mathbf{H g})}$ value for a time span of 50 years from 1959 to 2009. The calculated $\mathrm{Hg}$ concentrations were validated using the published observed data for the occurrence of $\mathrm{Hg}$ 


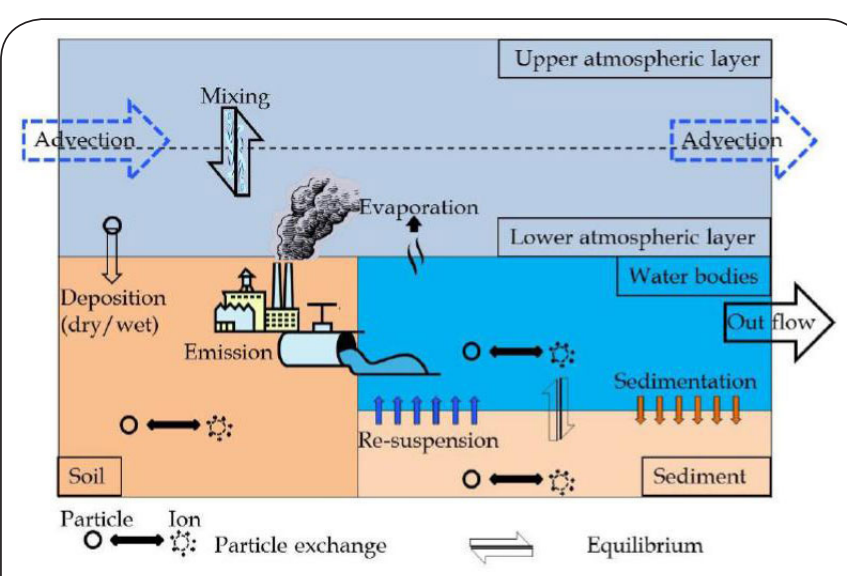

Figure 3. Diagrammatic explanation of OBMM and the chemical phenomena considered.

in the environment to evaluate the reliability of the OBMM calculations. Additional OBMM calculations were performed for the $\mathbf{K}_{\mathbf{d}(\mathbf{H g})}$ values obtained for the different samples of sediment and soil. The calculated concentrations based on different $\mathbf{K}_{\mathbf{d}(\mathrm{Hg})}$ values were then compared with the observed data to study the sensitivity of the OBMM calculations to the $\mathbf{K}_{\mathbf{d}(\mathbf{H g})}$ values.

\section{Results and discussion \\ Determination of $\mathrm{K}_{\mathrm{d}(\mathrm{Hg})}$}

The initial $\mathrm{pH}$ and temperature measured at the sampling sites are given in Table 1. During the shaking experiments, the temperature was maintained at $25^{\circ} \mathrm{C}$ to avoid temperature changes affecting the chemical behavior of $\mathrm{Hg}$. Measurements of the TOC were taken in the control samples after the shaking experiments to investigate the amount of organic materials present in the samples because the adsorption-desorption processes of metals are affected by the presence of organic matter [17].

Among the three different samples studied, the soil-Milli- $Q$ water (control) sample had the highest TOC measurement of $370 \mathrm{mg} \mathrm{L}^{-1}$, sediment-Milli- $Q$ water (control) sample had 23 $\mathrm{mg} \mathrm{L}^{-1}$, and the sand-Milli-Q water (control) sample had $9.9 \mathrm{mg}$ $\mathrm{L}^{-1}$. These evaluations were carried out with the assumption that $\mathrm{Hg}$ will acquire equilibrium between the aqueous and solid phases of the sample after the shaking experiments and the evaporation of $\mathrm{Hg}$ into the air inside the glass bottles is negligible because of the low volume of air in the glass bottles and the low concentrations of $\mathrm{Hg}$ spiked. When deciding the range of the spiking dose for the preliminary evaluation, the following facts had to be considered. If the concentration in the sample is too low, then the forward reaction (adsorption) becomes slower, resulting in a prolonged shaking time for the system to reach equilibrium; the chemical analysis of $\mathrm{Hg}$ also becomes more difficult at lower concentrations [18]. If the spiking dose is higher, then the solid phases of the samples might become saturated with $\mathrm{Hg}$. Therefore, considering the reported occurrences of $\mathrm{Hg}$ in soil ranging from 2-900 $\mathrm{g} \mathrm{kg}^{-1}$ [22], the range of the $\mathrm{Hg}$ spiking was set at $250-1000 \mathrm{~L} \mathrm{~L}^{-1}$ in the preliminary evaluation.

Figure 4 summarizes the results obtained from the shakingbatch experiments to evaluate the $\mathbf{K}_{\mathbf{d}(\mathrm{Hg})}$. The concentrations of $\mathrm{Hg}$ in the aqueous and solid phases of the samples were used to calculate the $\mathbf{K}_{\mathbf{d}(\mathrm{Ha})}$ values for each sub-sample. The calculated $\mathbf{K}_{\mathbf{d}(\mathrm{Hg})}$ values for the soil sample were plotted against the spiked volumes of $\mathrm{Hg}$ per $1 \mathrm{~L}$ of Milli- $\mathrm{Q}$ water, as shown in Figure 4. Variations in the $\mathbf{K}_{\mathbf{d}(\mathbf{H g})}$ values were extrapolated with the best fitted second-order polynomial curve to observe the trend of the $\mathbf{K}_{\mathrm{d}(\mathrm{Hg})}$ at higher spiking doses than $1000 \mu \mathrm{L} \mathrm{L}^{-1}$. Similar trends have been reported in another publication by Yin Y. et al., in 1997 [23]. Because the greatest portion of the LBYRB is composed of land, the soil sample was selected as the representative sample. After 3 days of shaking at $40 \mathrm{rpm}$, $36 \mu \mathrm{g} \mathrm{kg}^{-1}$ of Hg was detected in the control sample for soil, but the amount of $\mathrm{Hg}$ released to the Milli- $\mathrm{Q}$ water media from the soil was more than 250 times smaller, showing that the $\mathrm{Hg}$ already existing in the sample was hardly involved in the adsorption-desorption reaction. The loam texture of the soil and the presence of higher organic content results in the lower desorption of $\mathrm{Hg}$ from the soil [23]. At the 1000 $\mu \mathrm{L} \mathrm{L}^{-1}$ spiking dose, the soil sample showed a maximum $\mathbf{K}_{d}$ $(\mathrm{Hg})$ value for the sample of 65.8. Considering this result and the kinetics of the adsorption-desorption reactions, $1000 \mu \mathrm{L}$ $\mathrm{L}^{-1}$ was chosen as the spiking dose to reduce the elongated time for $\mathrm{Hg}$ to reach equilibrium and to avoid saturating the solid phase [23]. Confirmative experiments were performed for shaking periods of 15,22 , and 30 days to evaluate the $\mathbf{K}_{\mathbf{d}(\mathbf{H g})}$ values for prolonged shaking periods. The experimental conditions applied in this step are shown in Figure 2, and the $\mathbf{K d}(\mathbf{1 - 3})$ values were calculated from the $\mathrm{Hg}$ concentrations obtained from the chemical analysis of the soil and Milli- $Q$ water samples. Line $\mathbf{A}-\mathbf{A} \mathbf{1}$ of Figure $\mathbf{4}$ shows the variation in the $\mathbf{K}_{d}$ values versus the shaking periods of 15,22 , and 30 days, where $\mathbf{K d} \mathbf{d}_{(1)}$ $=68.4, \mathbf{K}_{\mathbf{d}(2)}=77.1$ and $\mathbf{K}_{\mathrm{d}(3)}=84.1$ represent the $\mathbf{K}_{\mathrm{d}(\mathrm{Hg})}$ values for the samples with shaking durationsof 15, 22, and 30 days, respectively. From the $\mathbf{K}_{\mathrm{d}(1-3)}$ values, the rounded $\mathbf{K}_{\mathrm{d}(3)}$ value $(=80)$ was used in the OBMM simulations to evaluate the $\mathrm{Hg}$ concentration in the LBYRB, assuming that the $\mathrm{Hg}$ is in equilibrium within the aqueous and solid phases of the sample after 30 days of shaking.

It was important to study samples collected from other representative geographic locations in the LBYRB area with different soil textures to observe their variations in the $\mathbf{K}_{\mathrm{d}(\mathbf{H g})}$ values and to evaluate the sensitivity of the OBMM to the $\mathbf{K d}$ (Hg) values obtained from those samples. The properties of these samples are shown in Table 1. The preliminary evaluation of their $\mathbf{K}_{\mathbf{d}(\mathrm{Hg})}$ values was performed with the experimental conditions given in Figure 2. After 3 days of shaking, in both the control samples of the sediment and sand, the release of $\mathrm{Hg}$ into the Milli-Q water media was not detectable. In the sub-samples of the sediment, the maximum $\mathbf{K}_{\mathbf{d}(\mathbf{H g})}$ value was 
Table 1. Details of the sampling sites and sample properties.

\begin{tabular}{|c|c|c|c|c|}
\hline \multicolumn{2}{|c|}{ Sample Properties } & Sampling Point 1 & Sampling Point 2 & Sampling Point 3 \\
\hline \multirow{2}{*}{\multicolumn{2}{|c|}{ Location }} & Osaka University & Ina River & Ashiya Beach \\
\hline & & Suita City & Ikeda City & Ashiya City \\
\hline \multirow[t]{2}{*}{ Coordinates } & $\mathrm{N}$ & $34^{0} 49.299^{`}$ & $34^{0} 51.538^{`}$ & $34^{0} 42.454^{`}$ \\
\hline & $\mathrm{E}$ & $135^{0} 31.364^{\circ}$ & $135^{\circ} 24.006^{\prime}$ & $135^{\circ} 18.613^{\prime}$ \\
\hline \multicolumn{2}{|c|}{ Samples Collected } & $\begin{array}{l}\text { Ground Soil } \\
\text { (10 cm below surface) }\end{array}$ & $\begin{array}{l}\text { River Sediments } \\
\text { (1 } \mathrm{m} \text { from shore line) }\end{array}$ & $\begin{array}{l}\text { Sea sediments } \\
\text { ( } 1 \mathrm{~m} \text { from shore line) }\end{array}$ \\
\hline \multicolumn{2}{|l|}{--} & River water & River water & \\
\hline \multirow{2}{*}{\multicolumn{2}{|c|}{$\begin{array}{l}\text { Sample Temperature }\left({ }^{\circ} \mathrm{C}\right) \\
{ }^{*} 26\end{array}$}} & 20 & 26 & 23 \\
\hline & & -- & -- & -- \\
\hline \multicolumn{2}{|l|}{$\mathrm{pH}$} & 7.2 & 7.8 & 8.2 \\
\hline \multirow{2}{*}{\multicolumn{2}{|c|}{$c_{-1} T_{0}$}} & -- & -- & -- \\
\hline & & Loam soil & Slit/Clay & Fine sand \\
\hline
\end{tabular}

*Secondary evaluation.

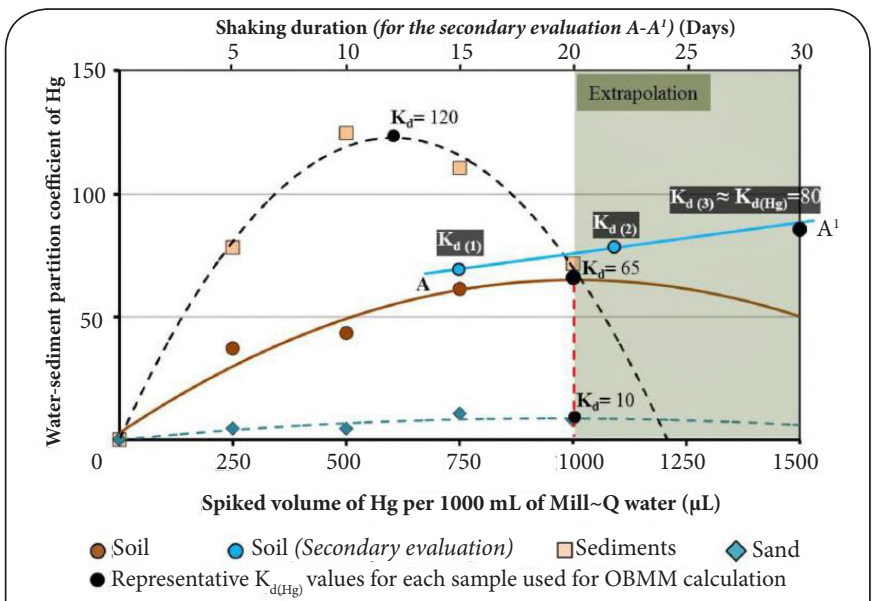

Figure 4. Variation of the $\mathbf{K}_{\mathbf{d}(\mathrm{Hg})}$ against the spiking dose of $\mathrm{Hg}$ to soil, sediment, and sand in the Milli-Q water systems. The variation of the $\mathrm{K}_{\mathrm{d}(1,2 \& 3)}$ over the shaking duration for a $1000 \mu \mathrm{L} \mathrm{L}^{-1}$ spiking dose.

125 at the $\mathrm{Hg}$ spiking dose of $500 \mu \mathrm{L} \mathrm{L}^{-1}$; then, the $\mathbf{K}_{\mathbf{d}(\mathbf{H g})}$ value started to decrease. The reasons for this behavior are either that the sediment samples became saturated at the higher spiking doses of $\mathrm{Hg}$ over $500 \mathrm{LL} \mathrm{L}^{-1}$, so the adsorption process of $\mathrm{Hg}$ was stopped, or the desorption of $\mathrm{Hg}$ from the sediment, releasing it to the aqueous phase. Sub-samples of the sand reached a maximum $\mathbf{K}_{\mathbf{d}(\mathbf{H g})}$ value of 10.6 at the $\mathrm{Hg}$ spiking dose of $750 \mu \mathrm{L} \mathrm{L}^{-1}$. Therefore, the $\mathbf{K}_{\mathbf{d}(\mathbf{H g})}$ values of 10,65 , and 120 were selected to represent the samples of sand, soil, and sediment, respectively. The OBMM calculations for these $\mathbf{K}_{\mathbf{d}}$ $(\mathrm{Hg})$ values were compared with the OBMM calculation carried out with $\mathbf{K}_{\mathbf{d}(\mathbf{H g})}$ of 80 . The accuracy of these results could be improved by evaluating the $\mathbf{K}_{\mathbf{d}(\mathbf{H g})}$ between the aqueous and solid phases of samples collected for different geographic areas in the study site. In this study, the number of replicates was one; therefore, increasing the number of replicates for the sub-samples would have increased the accuracy of the $\mathbf{K}_{\mathbf{d}(\mathbf{H g})}$ evaluation. Saturation levels of the solid phase samples have to be studied in detail to confirm the occurrence of the desorption process. Additionally, further studies about the composition of the solid phase samples would have given more detailed explanations of the behavior of $\mathrm{Hg}$ between these two phases.

Hg emission amounts, OBMM simulations, and sensitivity evaluation

In order to perform OBMM simulations, $\mathrm{Hg}$ emissions to the atmosphere, water, and soil from 1959 to 2009 were calculated and the total $\mathrm{Hg}$ emissions for that time span are shown in Figure 5. Emissions of $\mathrm{Hg}$ have been controlled since 1973 and from 1990 to 2000 there was no record of $\mathrm{Hg}$ emissions until the PRTR started recording the emissions in 2001. From 2001 to 2009, the $\mathrm{Hg}$ emissions recorded in the registered PRTR category was zero. However, in the non-registered PRTR emissions category, comparatively smaller emission amounts from industries having less than 20 employees and with less than 1 ton per year annual $\mathrm{Hg}$ consumptions were recorded from 2001 to 2009 [21]. Therefore the averaged total hg emissions from 2001 to 2009 were used to represent the $\mathrm{Hg}$ emission from 1991 to 2000, as shown in Figure 5.

In Figure 6, the calculated $\mathrm{Hg}$ concentrations by the OBMM with the experimentally evaluated $\mathbf{K}_{\mathbf{d}(\mathbf{H g})}$ value $(=80)$ for the atmosphere, water, soil, and sediments are shown in $\log _{10}$ scale for a 50-year span. Atmospheric $\mathrm{Hg}$ concentrations were reported from $2.54 \times 10^{-6}$ to $1.20 \times 10^{-5} \mathrm{mmol} \mathrm{m}^{-3}$, while concentrations in water ranged from $1.27 \times 10^{-2}$ to $6.66 \times 10^{-2}$ $\mu \mathrm{mol} \mathrm{m}^{-3}$. In the soil, the $\mathrm{Hg}$ concentration varied from $5.78 \times 10^{-2}$ to $6.96 \times 10^{-1} \mu \mathrm{mol} \mathrm{kg}{ }^{-1}$, and in the sediments, the $\mathrm{Hg}$ concentration varied from $3.03 \times 10^{-1}$ to $5.57 \mu \mathrm{mol} \mathrm{kg}{ }^{-1}$. According to the temporal concentration trends shown by the results in Figure 6, accumulation of $\mathrm{Hg}$ in the soil and sediments can be seen until the1970s; after that time, the 


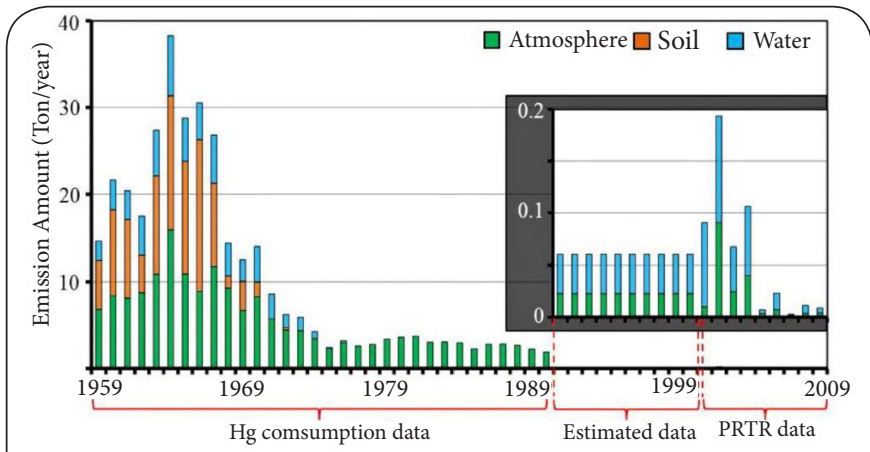

Figure 5. Total $\mathrm{Hg}$ emissions to the atmosphere, soil, and water from 1959 to 2009 .

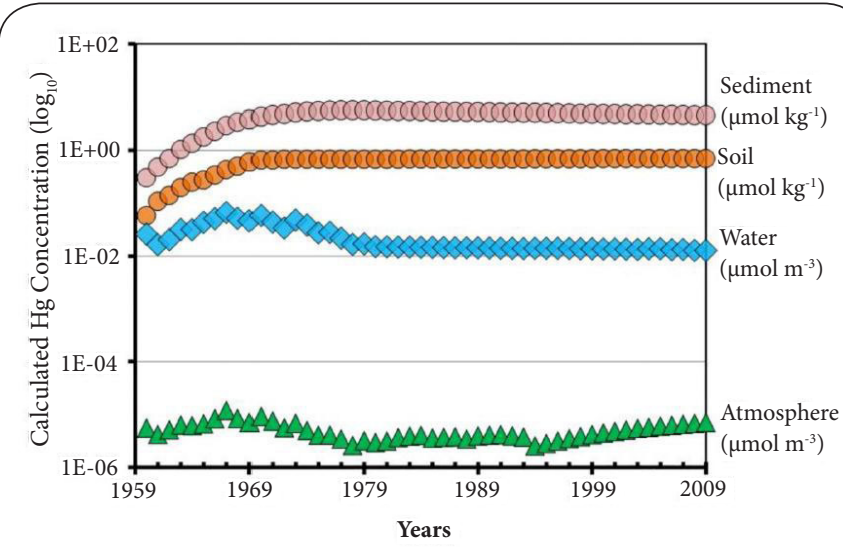

Figure 6. Calculated concentrations for $\mathrm{Hg}$ from 1959 to 2009 in the atmosphere, water, soil, and sediments using the OBMM with $\mathbf{K}_{\mathbf{d}(\mathrm{Hg})}=80$.

concentrations became constant due to the controlled $\mathrm{Hg}$ emissions. In the last 30 years of the study, the $\mathrm{Hg}$ concentrations in water decreased and have become stable compared to the first 20 years. This decrease is due to the adsorption of a certain portion of $\mathrm{Hg}$ into the sediments and transportation to the ocean. It was observed that with controlled $\mathrm{Hg}$ emissions, the concentrations of $\mathrm{Hg}$ in the water became constant. The atmospheric $\mathrm{Hg}$ concentration showed relatively small variations during the time span of this study. The lower accuracy of the estimation methods in the non-registered PRTR data and the long-range atmospheric transport of $\mathrm{Hg}$ from the Asian continent might have caused these variations in the last three decades [24].

Due to the strict management practices applied to the consumption and emission of $\mathrm{Hg}$ from the 1970s, a distinctive increase in the $\mathrm{Hg}$ concentrations in the environmental media is not visible except for relatively small variations in the atmospheric $\mathrm{Hg}$ concentrations. These calculated results were validated by comparing them with the observed data for the environmental $\mathrm{Hg}$ concentrations. The observed $\mathrm{Hg}$ concentrations in the atmosphere in Osaka Prefecture from 2001 to 2009 and the calculated $\mathrm{Hg}$ concentrations by the OBMM simulations for the respective years are shown in the Appendix 2 Figure (A) 1 in the Supplementary Data [25].

The observed data were monitored at suspected locations for the occurrences of higher $\mathrm{Hg}$ concentrations, but the OBMM calculations seem to produce a general value for the whole study area; therefore, the calculated $\mathrm{Hg}$ concentrations represent the lower range of the observed $\mathrm{Hg}$ concentrations in the atmosphere. Calculated $\mathrm{Hg}$ concentrations ( with $\mathbf{K}_{\mathrm{d}(\mathrm{Hg})}=80$ ) for all of the environmental media for the year 2009 were compared with the observed data for all of the environmental media for the same year, as shown in the Figure 7 [25-27].

The calculated $\mathrm{Hg}$ concentrations fall within the range of the observed $\mathrm{Hg}$ concentrations, validating the reliability of the calculated results. To observe the effect of the $\mathbf{K}_{\mathrm{d}(\mathrm{Hg})}$ value on the

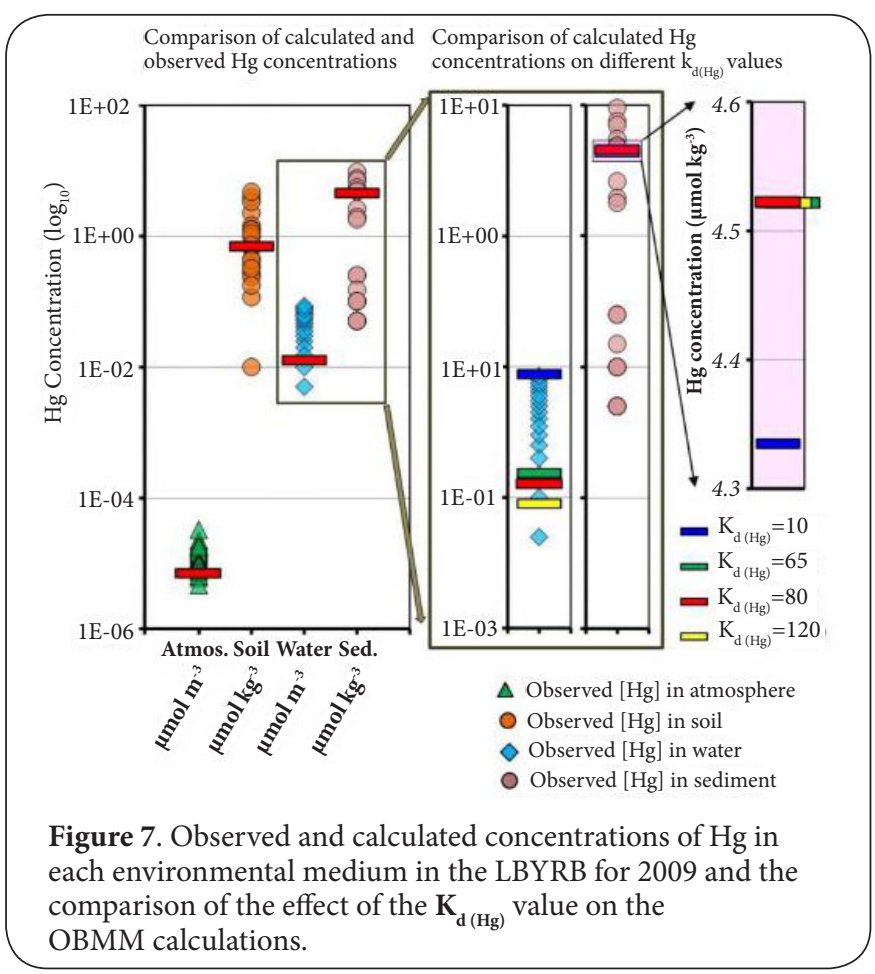

OBMM calculations, simulations were carried out with different $\mathbf{K}_{\mathbf{d}_{(\mathrm{Hg})}}$ values obtained from the $\mathbf{K}_{\mathrm{d}(\mathrm{Hg})}$ evaluation experiments $\left(\mathbf{K}_{\mathrm{d}(\mathrm{Hg})}=10,65,80\right.$, and 120) for the year 2009. The results were compared with the observed $\mathrm{Hg}$ concentrations in water and sediment, as shown in Figure 7. The observed $\mathrm{Hg}$ concentrations in water varied from $4.99 \times 10^{-3}$ to $8.47 \times 10^{-2} \mu_{\mathrm{mol} \mathrm{m}}^{-3}$, with an average of $4.49 \times 10^{-2} \mu \mathrm{mol} \mathrm{m}^{-3}$. The calculated $\mathrm{Hg}$ concentration with $\mathbf{K}_{\mathrm{d}(\mathrm{Hg})}=10$ provided higher concentrations than this range, while the calculated $\mathrm{Hg}$ concentrations with $\mathbf{K}_{\mathbf{d}(\mathbf{H g})}=65$ and $\mathbf{K}_{\mathrm{d}(\mathrm{Hg})}=80$ provided results closer to the average observed $\mathrm{Hg}$ concentration. In the case of $\mathbf{K}_{\mathbf{d}(\mathrm{Hg})}=120$, the calculated $\mathrm{Hg}$ concentration resulted in the lowest from the average observed concentration as shown in Figure 7. In sediment, the observed $\mathrm{Hg}$ concentrations varied from 
$9.97 \times 10^{-2}$ to $9.47 \mu \mathrm{mol} \mathrm{kg}{ }^{-1}$ with an average of $1.96 \mu \mathrm{mol} \mathrm{kg}{ }^{-1}$. The calculated $\mathrm{Hg}$ concentrations in sediment with all $\mathbf{K}_{\mathbf{d}(\mathrm{Hg})}$ values were between the range of the observed $\mathrm{Hg}$ concentration. As described with the magnification in Figure 7, $\mathbf{K}_{\mathrm{d}(\mathrm{Hg})}=10$ resulted in $4.33 \mu \mathrm{mol} \mathrm{kg}{ }^{-1}$. In the case of $\mathbf{K}_{\mathrm{d}(\mathrm{Hg})}=65$, 80 , and 120 , the calculated concentration of $\mathrm{Hg}$ in sediments was $4.52 \mu \mathrm{mol} \mathrm{kg}^{-1}$, showing that thecalculated concentrations of $\mathrm{Hg}$ in the sediments were not affected by higher $\mathbf{K}_{\mathrm{d}(\mathrm{Hg})}(\geq 65)$ values but were affected by lower $\mathbf{K}_{\mathrm{d}(\mathrm{Hg})}(10 \leq 65)$ values. It was apparent that the calculated $\mathrm{Hg}$ concentrations in water were affected by the $\mathbf{K}_{\mathbf{d}(\mathbf{H g})}$ value, which was clearly affected by the soil types. Each respective $\mathbf{K}_{\mathbf{d}(\mathbf{H g})}$ value obtained from samples with different geographic characteristics provided a different calculated $\mathrm{Hg}$ concentration, and $\mathbf{K}_{\mathbf{d}(\mathrm{Hg})}=80$ provided a generalized calculated $\mathrm{Hg}$ concentration in water for the whole LBYRB area. These results showed that incorporating the experimentally evaluated $\mathbf{K}_{\mathbf{d}(\mathbf{H g})}$ into the OBMM calculation provided calculated $\mathrm{Hg}$ concentrations in water and sediments that were much closer values to the average observed $\mathrm{Hg}$ concentration, there by proving that the OBMM calculations have improved.

Many chemical coefficients other than the $\mathbf{K}_{\mathrm{d}(\mathrm{Hg})}$ affect the chemical behavior of $\mathrm{Hg}$ in the environment, so the OBMM surely can be improved by experimentally evaluating and incorporating those experimentally evaluated coefficients in to the OBMM calculations. The availability of the emission data and observed data for the occurrences of $\mathrm{Hg}$ in different environmental media is really important to improve the accuracy of the OBMM calculations and the validation of the calculated results of the model.

\section{Conclusion}

The concentrations of $\mathrm{Hg}$ in four environmental media, namely the atmosphere, water, soil, and sediments, of the LBYRB were evaluated using an OBMM. Annual emissions of $\mathrm{Hg}$ were calculated using the literature on $\mathrm{Hg}$ consumption and PRTR data for a 50-year span. Laboratory-scale experiments were carried out to evaluate the $\mathbf{K}_{\mathbf{d}(\mathrm{Hg})}$ between the aqueous and solid phases of the environment, and an experimentally determined $\mathbf{K}_{\mathbf{d}(\mathbf{H g})}$ value $(=80)$ was incorporated in to the OBMM. The concentrations of environmental $\mathrm{Hg}$ were calculated using the annual emission amounts and the OBMM. The calculated $\mathrm{Hg}$ concentrations were compared with the observed $\mathrm{Hg}$ concentrations in the study area to validate the accuracy of the OBMM calculations. Variations were observed in the calculated atmospheric $\mathrm{Hg}$ concentrations while in the sediment and soil, accumulation of $\mathrm{Hg}$ was observed. Except for the atmosphere, the calculated $\mathrm{Hg}$ concentrations in the soil, water, and sediment became constant over the last three decades of the study span, due to the controlled consumption of $\mathrm{Hg}$. The sensitivity of the OBMM calculations to the $\mathbf{K}_{\mathbf{d}(\mathrm{Hg})}$ value was studied by comparing the calculated $\mathrm{Hg}$ concentrations on different $\mathbf{K}_{\mathrm{d}(\mathbf{H g})}$ values representing different soil types. The results showed that the experimentally evaluated $\mathbf{K}_{\mathbf{d}(\mathbf{H g})}$ value (=80) improved the accuracy of the OBMM calculations by providing a generalized $\mathbf{K}_{\mathbf{d}(\mathbf{H g})}$ value representing the whole study area. Therefore, the objective of this study was successfully achieved. Furthermore, this study can be used to formulate detailed studies to investigate the occurrences of environmental $\mathrm{Hg}$. This study will provide sufficient details about $\mathrm{Hg}$ in the environment to the interested parties, such as authorities responsible for environmental monitoring and management, so that they can proceed with better environmental management practices to mitigate environmental pollution. By modifying the model, the environmental condition of other pollutants can be evaluated. This makes the environmental monitoring process more successful and eventually protects the environment.

\section{Additional files \\ Supplementray Data}

Competing interests

The authors declare that they have no competing interests.

Authors' contributions

\begin{tabular}{|l|c|c|c|c|c|}
\hline Authors' contributions & BA & AK & HS & HO & YI \\
\hline Research concept and design & $\checkmark$ & $\checkmark$ & $\checkmark$ & $\checkmark$ & $\checkmark$ \\
\hline Collection and/or assembly of data & $\checkmark$ & -- & -- & $\checkmark$ & -- \\
\hline Data analysis and interpretation & $\checkmark$ & -- & -- & $\checkmark$ & -- \\
\hline Writing the article & $\checkmark$ & -- & -- & -- & -- \\
\hline Critical revision of the article & $\checkmark$ & $\checkmark$ & $\checkmark$ & $\checkmark$ & $\checkmark$ \\
\hline Final approval of article & $\checkmark$ & $\checkmark$ & $\checkmark$ & $\checkmark$ & $\checkmark$ \\
\hline
\end{tabular}

Acknowledgement

The chemical analysis of $\mathrm{Hg}$ in this research was carried out at a laboratory facility of Teijin Eco Science Ltd. We wish to thank their staff for the supportive collaboration and advice.

\section{Publication history}

Editor: Aysegul Tanik, Istanbul Technical University, Turkey. Senior Editor: Mallikarjuna Nadagouda, US Environmental Protection Agency, USA.

EIC: Robert Boyd Harrison, University of Washington, USA. Received: 25-Mar-2014 Final Revised: 16-Apr-2014

Accepted: 05-May-2014 Published: 05-Jun-2014

\section{References}

1. Hansen J, Russell G, Rind D, Stone P, Lacis A, Lebedeff S, Ruedy R and Travis L. Efficient Three-Dimensional Global Models for Climate Studies: Models I and II. Mon. Wea. Rev. 1983; 111:609-662. I Article

2. Byun D and Schere K L. Review of the Governing Equations, Computational Algorithms, and Other Components of the Models-3 Community Multiscale Air Quality (CMAQ) Modeling Systems. Appl. Mech. Rev. 2006; 59:57-77. | Article

3. Kondo A, Yamamoto M, Inoue $Y$ and Ariyadasa BHAKT. Evaluation of lead concentration by one-box type multimedia model in Lake BiwaYodo River basin of Japan. Chemosphere. 2013; 92:497-503. | Article | PubMed

4. Harada M. Minamata disease: methylmercury poisoning in Japan caused by environmental pollution. Crit Rev Toxicol. 1995; 25:1-24. | Article | PubMed 
5. Environmental Health and Safety Division, Environmental health Department, Ministry of the Environment, Japan: Lessons from Minamata Disease and mercury Management in Japan. Ministry of the Environment, Japan. 2011. I Pdf

6. Sakata M and Marumoto $\mathrm{K}$. Wet and dry deposition fluxes of mercury in Japan. Atmos Environ. 2005; 39:3139-3146. I Article

7. Ministry of the Environment, Japan. Water/ Soil/ Ground Environment Ministry of the Environment, Japan 2014. I Website

8. United Nations Environmental Program. Minamata convention on mercury. Minamata Convention on Mercury 2013. I Website

9. World health organization. Mercury and health. World health organization 2013. | Website

10. Khandakar H A R, Hiroshi M and Kambara S. Atmospheric mercury dispersion modelling from two nearest hypothetical point sources. International Journal of Energy and Environment. 2012; 3:181-194. I Pdf

11. Lindstrom M. Distribution of particulate and reactive mercury in surface waters of Swedish forest lakes-an empirically based predictive model. Ecol Model. 2001; 136:81-93. I Article

12. Stein E D, Cohen Y and Winer A M. Environmental distribution and transformation of mercury compounds. Crit Rev Env Sci Tec. 1996; 26:143. | Article

13. Brigham ME, Wentz DA, Aiken GR and Krabbenhoft DP. Mercury cycling in stream ecosystems. 1. Water column chemistry and transport. Environ Sci Technol. 2009; 43:2720-5. I Article I PubMed

14. Sudo M, Kunimatsu T and Okubo T. Concentration and loading of pesticide residues in Lake Biwa basin (Japan). Water Res. 2002; 36:31529. | Article I PubMed

15. Japanese Industrial Standard Committee: JISK0050-General rules for chemical analysis. Japanese Standard Association 2011.

16. Suzuki T. Mercury Analysis Manual. Ministry of the Environment, Japan. 2004. I Pdf

17. Ramamoorthy $S$ and Rust B R. Heavy metal exchange processes in sediment-water systems. Environ Geol. 1978; 2:165-172. | Article

18. Louis J T. Equilibrium at Environmental Interfaces. Wiley -Interscience Publication, Chemodynamics-Environmental Movement of Chemicals in Air, Water, and Soil. 1979; 47-52.

19. Kida A. Usage of Mercury in Japan and the world (In Japanese). Ministry of the Environment, Japan 2012.

20. Takahashi F, Yamagata M, Yasuda K and Kida A. Impact of mercury emissions from the incineration of automobile shredder residue in Japan. App/ Geochem. 2008; 23:584-593. | Article

21. Ministry of the Environment, Japan. PRTR Information Plaza. Ministry of the environment, Japan 2014. I Website

22. Nakagawa R. Forms and exchanges of residual mercury in soil (In Japanese). Global Environment. 2008; 13:245-252.

23. Yin $\mathrm{Y}$, Allen $\mathrm{H} E$ and Huang $C \mathrm{P}$. Kinetics of Mercury (II) Adsorption and desorption on Soil. Environ Sci Technol. 1997; 31:496-503. I Article

24. Jaffe D, Prestbo E, Swartzendruber P, Weiss-Penzias P, Kato S, Takami A, Hatakeyama $S$ and Kajii Y. Export of atmospheric mercury from Asia. Atmos Environ. 2005; 39:3029-3038. I Article

25. Environment, agriculture and forestry, marine product division: Monitoring survey of harmful atmospheric pollutants in Osaka 2010(In Japanese). Osaka Prefectural Government 2011.

26. Global environment and marine division: Atmospheric heavy metal 2012. (In Japanese). Japan Meteorological Agency 2013.

27. Environment, agriculture and forestry, marine product division: Monitoring survey of river sediments in Osaka 2010(In Japanese) Osaka Prefectural Government 2011.

\section{Citation:}

Ariyadasa BHAKT, Kondo A, Shimadera H, Ochi $\mathrm{H}$ and Inoue Y. Evaluation of mercury concentration in the lake biwa-yodo river basin by a one-box multimedia model and model sensitivity on the experimentally determined water-sediment partition coefficient. $J$ Environ Eng Ecol Sci. 2014; 3:3.

http://dx.doi.org/10.7243/2050-1323-3-3 